\title{
Macular Hole Surgery in Dome-Shaped Maculopathy
}

\section{Sol Lee \\ Ron P Gallemore}

Retina Macula Institute, Torrance, CA, 90503, USA
Correspondence: Ron P Gallemore 420 I Torrance Blvd, Suite 220, Torrance, CA, 90503, USA

Tel + I 3I0 4I3-7020

Email rongallemoremd@gmail.com
Purpose: To present a successful case of macular hole surgery in a patient with domeshaped maculopathy (DSM).

Observations: Patient with DSM had successful closure of a full-thickness macular hole with surgery. There was persistent subretinal fluid after the surgery, which showed some response to a combination of a diuretic and a nonsteroidal anti-inflammatory drug (NSAID). Conclusions and Importance: Full-thickness macular hole in DSM may be effectively managed with modern surgical techniques.

Keywords: macular hole surgery, dome-shaped maculopathy, serous retinal detachment, spironolactone, NSAID

\section{Introduction}

Dome-shaped maculopathy (DSM) was first described in highly myopic patients by Gaucher et al in 2008. ${ }^{1}$ It is associated with thickening of the sclera, which leads to a convex protrusion of the macula creating a dome. ${ }^{2}$ One common complication of DSM is a serous retinal detachment (SRD) that develops over the macula, ${ }^{3,4}$ though its exact mechanism remains a mystery. It has been postulated that DSM may be an adaptive or compensatory response to large axial length in high myopes ${ }^{5,6}$ and the serous detachment may be the result of retinal dysfunction and fluid obstruction caused by scleral thickening. ${ }^{5}$ Attempts to treat this with various interventions including laser, diuretics, anti-inflammatory drops and even surgery have met with variable success. ${ }^{7-13}$ Recently, we encountered a case of dome-shaped maculopathy associated with macular hole formation. A standard approach of surgery including vitrectomy, internal limiting membrane (ILM) peeling with triamcinolone acetate visualization, and gas tamponade was successful.

\section{Case Report}

A 62-year-old myopic female with keratoconus presented with complaints of changes in visual acuity in the right eye for 5 months with distortion and difficulty reading fine print. She had a history of Intacs placed in the right eye 10 years prior, and had Intacs placed in the left with corneal cross-linking in both eyes when she noticed her vision change in the right eye. Her best-corrected visual acuity (BCVA) was 20/200-2 OD and 20/50 OS. Her intraocular pressures (IOP) were $15 \mathrm{mmHg}$ and $14 \mathrm{mmHg}$, respectively. The axial length measured $26.85 \mathrm{~mm}$ OD and $26.89 \mathrm{~mm}$ OS, and there were $2+$ nuclear sclerotic cataracts (NSC) in both eyes. The initial optical coherence tomography (OCT) scan showed a macular bulge indicative of 


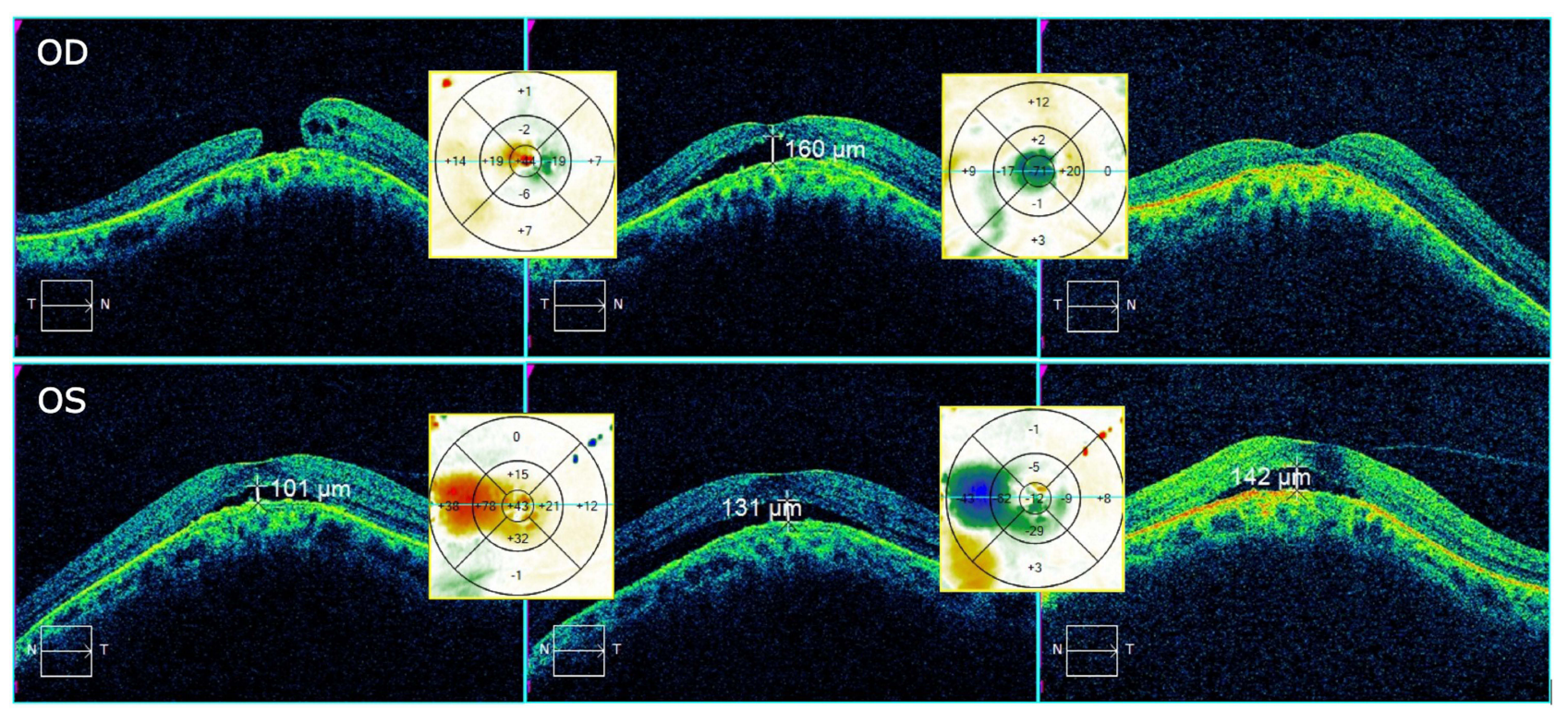

Figure I ( $L$ to R) Horizontal OCT cuts (with difference maps between images) preop, 2 month postop, and I year s/p vitrectomy. CMT was 2 I5, 3I7, 203 OD and 3I8, 36I, 335 OS respectively.

DSM in both eyes with a full-thickness macular hole in the right eye and subretinal fluid in the left eye (Figure 1). The central macular thickness (CMT) was 215 OD and 318 OS. Patient was started on spironolactone $25 \mathrm{mg}$ BID PO and underwent pars plana in the right eye 2 weeks later. The surgery was performed on September 10, 2018 at California Hospital in Los Angeles, California.

At the time of surgery, the posterior hyaloid membrane had been elevated and the Weiss ring removed. Attention was turned to the macula where triamcinolone acetate was injected over the macular area and the epiretinal membrane and underlying internal limiting membrane were removed with ILM forceps. An air fluid exchange with C3F8 gas was performed. On post-op day 1, the patient's IOP was 30 OD and acetazolamide 500mg QD PO was added for 2 months to treat both the pressure in the right eye and the subretinal fluid that was present in the left eye. Patient was compliant with 2 weeks of strict face-down positioning.

At 2 months post-op, BCVA was 20/60-1 OD and 20/ $40+1$ OS. There was $3+$ NSC, as well as $1+$ cortical cataract and $1+$ posterior subcapsular cataract $\mathrm{OD}$, and 2 + NSC OS. CMT was 317 OD and 361 OS. Patient had persistent subretinal fluid in both eyes, and she was subsequently started on an NSAID drop twice daily in both eyes. Patient underwent cataract surgery in the right eye at 9 months post op. At 1 year s/p vitrectomy, CMT was 203 OD and 335 OS. On the most recent examination, 32 months after vitrectomy and 23 months after cataract surgery, BCVA was 20/20 OD and 20/30 OS.

\section{Discussion}

We report a successful case of macular hole repair associated with DSM. A standard approach for macular hole repair was successfully utilized. Subretinal fluid from the DSM persisted after the surgery but responded to a combination of oral spironolactone and a topical NSAID drop. The mechanism of DSM remains a mystery, but the effective treatment options may imply that a mechanism of altered fluid transport across the $\mathrm{RPE}^{14}$ likely creates the fluid accumulation in the subretinal space associated with DSM. NSAID drops can accelerate fluid absorption across the RPE, ${ }^{15}$ as can diuretics including spironolactone and acetazolamide. ${ }^{16-19}$ Our patient is myopic, which can make macular hole surgery less effective as a staphyloma may further stretch the retina and impair closure. ${ }^{20}$ The dome-shaped scleral support in DSM may actually facilitate hole closure in the same way as a macular buckle. ${ }^{21}$ The subretinal fluid, however, would impair closure and the use of adjunctive therapies in this case may have contributed to our success.

Patient has had recovery of BCVA to 20/20 OD and 20/ 30 OS. The patient has a closed macular hole with resolved subretinal fluid in the right eye. The left eye has persistent subretinal fluid, though decreased nasally compared to its peak at 2 months post op (Figure 1). The 
decreased visual acuity in the left eye may be due in part to a combination of factors: the persistent SRF, her cataract, and her history of keratoconus. The presence of persistent subretinal fluid in the left eye may be secondary to the slightly longer axial length of $0.04 \mathrm{~mm}$ or due to vitreomacular adhesion, which may be causing traction on the macula and preventing further fluid absorption across the RPE. It is difficult to ascertain to what extent each of these factors play a role in the final visual acuity, but the fact that her vision is improved compared to her initial presentation with the decreased subretinal fluid suggests that the fluid may play a more significant role in the final outcome.

\section{Patient Consent}

We confirm that any aspect of the work covered in this manuscript that has involved human patients has been conducted with the ethical approval of all relevant bodies. Informed written consent has been obtained from all patients to have case details and any accompanying images published.

\section{Acknowledgments}

There are no acknowledgements we would like to make. No institutional approval was required for the publishing of this case report.

\section{Author Contributions}

All authors made a significant contribution to the work reported, whether that is in the conception, study design, execution, acquisition of data, analysis and interpretation, or in all these areas; took part in drafting, revising or critically reviewing the article; gave final approval of the version to be published; have agreed on the journal to which the article has been submitted; and agree to be accountable for all aspects of the work.

\section{Funding}

No grant support or funding was given.

\section{Disclosure}

The following authors have no financial or other disclosures: SL, RPG.

\section{References}

1. Gaucher D, Erginay A, Lecleire-Collet A, et al. Dome-shaped macula in eyes with myopic posterior staphyloma. Am J Ophthalmol. 2008;145(5):909-914. doi:10.1016/j.ajo.2008.01.012
2. Imamura Y, Iida T, Maruko I, Zweifel SA, Spaide RF. Enhanced depth imaging optical coherence tomography of the sclera in dome-shaped macula. Am J Ophthalmol. 2011;151(2):297-302. doi:10.1016/j.ajo.2010.08.014

3. Coco RM, Sanabria MR, Alegría J. Pathology associated with optical coherence tomography macular bending due to either dome-shaped macula or inferior staphyloma in myopic patients. Ophthalmologica. 2012;228(1):7-12. doi:10.1159/000336910

4. Viola F, Dell'Arti L, Benatti E, et al. Choroidal findings in dome-shaped macula in highly myopic eyes: a Longitudinal Study. Am J Ophthalmol. 2015;159(1):44-52. doi:10.1016/j. ajo.2014.09.026

5. Wallman J, Gottlieb MD, Rajaram V, Fugate-Wentzek LA. Local retinal regions control local eye growth and myopia. Science. 1987;237(4810):73-77. doi:10.1126/science.3603011

6. Gottlieb MD, Fugate-Wentzek LA, Wallman J. Different visual deprivations produce different ametropia and different eye shapes. Invest Ophthalmol Vis Sci. 1987;28(8):1225-1235.

7. Giacomelli G, Mencucci R, Sodi A, et al. Aflibercept in serous foveal detachment in dome-shaped macula: short-term results in a retrospective study. Ophthalmic Surg Lasers Imaging Retina. 2017;48(10):822-828. doi:10.3928/23258160-20170928-07

8. Lorenzo D, Arias L, Choudhry N, et al. Dome-shaped macula in myopic eyes: twelve-month follow-up. Retina. 2017;37(4):680-686. doi:10.1097/IAE.0000000000001222

9. Chinskey ND, Johnson MW. Treatment of subretinal fluid associated with dome-shaped macula. Ophthalmic Surg Lasers Imaging Retina. 2013;44(6):593-595. doi:10.3928/2325816020131010-01

10. Dirani A, Matet A, Beydoun T, Mantel I, Behar-Cohen F. Resolution of foveal detachment in dome-shaped macula after treatment by spironolactone: report of two cases and mini-review of the literature. Clin Ophthalmol. 2014;8:999-1002. doi:10.2147/OPTH. S62267

11. Arapi I, Neri P, Mariotti C, et al. Considering photodynamic therapy as a therapeutic modality in selected cases of dome-shaped macula complicated by foveal serous retinal detachment. Ophthalmic Surg Lasers Imaging Retina. 2015;46(2):217-223. doi:10.3928/2325816020150213-15

12. Soudier G, Gaudric A, Gualino V, Nardin M, Speeg-Schatz C, Gaucher D. Epiretinal membrane in dome-shaped macula complicated with serous retinal detachment: transient efficacy of surgery. Case Rep Ophthalmol. 2017;8(3):515-520. doi:10.1159/000481703

13. Battaglia Parodi M, Iacono P, Bandello F. Subthreshold laser treatment for serous retinal detachment in dome-shaped macula associated with pathologic myopia. Retina. 2018;38(2):359-363. doi:10.1097/ IAE.0000000000001524

14. Gallemore RP, Hughes BA, Miller SS. Retinal pigment epithelial transport mechanisms and their contributions to the electroretinogram. Prog Retin Eye Res. 1997;16(4):509-566. doi:10.1016/S1350-9462(96)00037-7

15. Khan NA, Atiqa K, Sobia K, Aisha K, Ahmed AK. Topical bromfenac in the treatment of central serous chorioretinopathy. $A d v$ Ophthalmol Vis Syst. 2017;7(7):00248. doi:10.15406/ aovs.2017.07.00248

16. Tsuboi S, Pederson JE. Experimental retinal detachment: X. Effect of acetazolamide on vitreous fluorescein disappearance. Arch Ophthalmol. 1985;103(10):1557-1558. doi:10.1001/ archopht.1985.01050100133034

17. Marmor MF, Maack T. Enhancement of retinal adhesion and subretinal fluid resorption by acetazolamide. Invest Ophthalmol Vis Sci. 1982;23(1):121-124.

18. Wolfensberger TJ, Dimitriev AV, Govardovskii VI. Inhibition of membrane-bound carbonic anhydrase decreases subretinal volume and pH. Doc Ophthalmol. 1999;97(3-4):261-271. doi:10.1023/ a:1002496223131 
19. Yamamoto F, Steinberg RH. Effects of intravenous acetazolamide on retinal pH in the cat. Exp Eye Res. 1992;54(5):711-718. doi:10.1016/ 0014-4835(92)90025-n

20. Suda K, Hangai M, Yoshimura N. Axial length and outcomes of macular hole surgery assessed by spectral-domain optical coherence tomography. Am J Ophthalmol. 2011;151(1):118-127. doi:10.1016/j. ajo.2010.07.007
21. Mura M, Iannetta D, Buschini E, de Smet MD. T-shaped macular buckling combined with $25 \mathrm{G}$ pars plana vitrectomy for macular hole, macular schisis, and macular detachment in highly myopic eyes. $\mathrm{Br}$ $J$ Ophthalmol. 2017;101(3):383-388. doi:10.1136/bjophthalmol2015-308124

\section{Publish your work in this journal}

The International Medical Case Reports Journal is an international, peer-reviewed open-access journal publishing original case reports from all medical specialties. Previously unpublished medical posters are also accepted relating to any area of clinical or preclinical science. Submissions should not normally exceed 2,000 words or 4 published pages including figures, diagrams and references. The manuscript management system is completely online and includes a very quick and fair peer-review system, which is all easy to use. Visit http://www.dovepress.com/testimonials.php to read real quotes from published authors. 